\title{
Evaluation of thermal performance parameters and representation of efficiency curves in solar air heaters.
}

\author{
[Ravi Kumar, Laljee Prasad, B.N. Prasad]
}

\begin{abstract}
Flat plate solar collectors of water heating and air heating types have been widely studied for variety of utilizations. Water heaters are mostly of water recirculation types, their thermal efficiency curves are represented with the conventional equations and methods. However, for solar air heaters, mostly being without recycling of air and which performance is very much mass flow rate dependent, the conventional equations and methods for evaluating and representing their performance become not so valid and useful. This papers represents and discusses the way of evaluation of performance of solar air heater of conventional and novel types together with the nature of performance curves obtained thereof.
\end{abstract}

Keywords - Thermal efficiency, performance parameters, plate efficiency factor, collector heat removal factor, fluid inlet and outlet temperature.

\section{Nomenclature:-}

$A_{c}$ collector area, $\mathrm{m}^{2}$

$C_{1} \quad$ Index $\mathrm{C}_{1}=4.6$ for single glass cover

$C_{p} \quad$ specific heat of fluid at constant pressure, $\mathrm{J} / \mathrm{kg} \mathrm{K}$

$C_{p}^{\prime} \quad$ specific heat of the media in calorimeter, $\mathrm{J} / \mathrm{kg}^{\circ} \mathrm{C}$

$D$ hydraulic diameter of collector duct, $\mathrm{m}$

d tube diameter, $m$

e artificial roughness height, $\mathrm{m}$

$e / D$ relative roughness height

$f_{1} \quad f_{1}=0.98\left[1.008 \tau \alpha+\left\{(1-\tau R) /\left(C_{1} \alpha\right)\right\}\right]$

$F$ fin efficiency factor

$F^{\prime} \quad$ collector efficiency factor

$F^{\prime \prime} \quad$ collector flow factor

$F_{R}$ heat removal factor

$F_{a v}$ equivalent to collector efficiency factor

$F_{R} U_{L} \quad$ slope of the thermal performance curve

Ravi Kumar (Research Scholar)

NIT, Jamshedpur

India

Dr. Laljee Prasad (Asst. Prof. Mech. Engg. Dept.)

NIT, Jamshedpur

India

Dr. B. N. Prasad (Prof. Mech. Engg. Dept.)

NIT, Jamshedpur

India
$F_{R}(\tau \alpha)$ intercept of the thermal performance curve

$G$ air mass flow rate per unit collector area, $\mathrm{kg} \mathrm{s}^{-1}$ $\mathrm{m}^{-2}$

$h$ heat transfer coefficient, $\mathrm{W} / \mathrm{m}^{2} \mathrm{~K}$

$I$ intensity of solar radiation, $\mathrm{W} / \mathrm{m}^{2}$

$k$ thermal conductivity of air, $\mathrm{W} / \mathrm{mK}$

$\dot{m}$ fluid flow mass rate, $\mathrm{kg} / \mathrm{s}$

$m^{\prime} \mathrm{kg} / \mathrm{m}^{2}$

$p \quad$ pitch of roughness element, $\mathrm{m}$

$p / e$ relative roughness pitch

$Q_{u} \quad$ incident solar energy, $\mathrm{W}$

$\mathrm{s}$ tube spacing, $\mathrm{m}$

$t_{a} \quad$ ambient temperature, ${ }^{\circ} \mathrm{C}$

$t_{i} \quad$ fluid inlet temperature, ${ }^{\circ} \mathrm{C}$

$t_{o} \quad$ fluid outlet temperature, ${ }^{\circ} \mathrm{C}$

$t_{m} \quad \mathrm{t}_{\mathrm{m}}=\left(\mathrm{t}_{\mathrm{i}}+\mathrm{t}_{0}\right) / 2,{ }^{\circ} \mathrm{C}$

$t_{a v} \quad \mathrm{t}_{\mathrm{av}}=\left(\mathrm{t}_{0}-\mathrm{t}_{\mathrm{i}}\right) / 2,{ }^{\circ} \mathrm{C}$

$\overline{t_{f}} \quad$ average fluid temperature, ${ }^{\circ} \mathrm{C}$

$\overline{t_{p}} \quad$ average plate temperature, ${ }^{\circ} \mathrm{C}$

$U_{L} \quad$ overall heat transfer coefficient, $\mathrm{W} / \mathrm{m}^{2}{ }^{\circ} \mathrm{K}$

$\tau \boldsymbol{\alpha}$ transmittance - absorptance product

$\boldsymbol{\delta} \quad$ fin thickness, $\mathrm{m}$

$\eta_{t h} \quad$ thermal efficiency

\section{Introduction:-}

Different configuration solar collectors (water heating and air heating types) are available in literature. Solar air heaters have gained attention in recent decades to improve its performance. Literature on top side artificially roughened solar air heater is extensively available [1]. Analysis of novel type of solar air heater is also available [2,3]. However, the conventional methods of representing performance of solar air heaters are not directly useful due to the reason that these usually operate without recycling of air. The present paper deals with the procedure and method of evaluation and representing the performance characteristics of such solar air heaters.

\section{Performance Evaluation Analysis:-}

Under quasi-steady state conditions, the useful thermal energy is obtained from the energy balance between the energy absorption rate of the absorber 
and the thermal energy losses directly and indirectly to the surroundings, written as:-

$Q_{u} / A_{c}=I(\tau \alpha)-U_{L}\left(\bar{t}_{p}-t_{a}\right)$

The difficulty in utilizing the above equation lies in the calculation of mean absorber plate temperature, $\bar{t}_{p}$, which is a function of the collector configuration, the incident solar radiation and the entering fluid conditions. Therefore, Eq. (1) is usually represented in a more practical form as:

$$
Q_{u} / A_{c}=F_{R}\left[I(\tau \alpha)-U_{L}\left(t_{i}-t_{a}\right)\right]
$$

where the heat removal factor, $F_{R}$ is written as:

$F_{R}=\dot{m} C_{p}\left(t_{o}-t_{i}\right) / A_{c}\left[I(\tau \alpha)-U_{L}\left(t_{i}-t_{a}\right)\right]$

The widely used basic Eq. (2) of [4,5] is modified to include thermal efficiency as:

$\eta_{t h}=F_{R}\left[(\tau \alpha)-U_{L}\left(t_{i}-t_{a} / I\right)\right]$

Eq. (4) expresses the thermal efficiency of the collector in terms of two major operating parameters, incident solar radiation normal to the collector plate and the temperature difference $\left(t_{i}-t_{a}\right)$. Eqs. (2) and (4) are widely used to compare the performance characteristics of different types of collectors and to investigate for the effect of various parameters. Heat removal factor, $F_{R}$, a function of plate efficiency factor $F^{l}$, is defined [5] as:

$F^{\prime}=h / h+U_{L}$

The values of $F$, is a strong function of configuration parameters [8]. Collector flow factor, $F^{\prime \prime}$, has been included [8] to present equation as under:

$F_{R}=\dot{m} C_{p} / A_{C} U_{L} \cdot\left[1-\exp ^{-\left(A_{C} U_{L} F^{\prime} / \dot{m} C_{p}\right)}\right]$

such that,

$F^{\prime \prime}=F_{R} / F^{\prime}=\dot{m} C_{p} / A_{C} U_{L} F^{\prime} \cdot\left[1-\exp ^{-\left(A_{C} U_{L} F^{\prime} / \dot{m} C_{p}\right)}\right]$

The collector flow factor, $F^{\prime \prime}$, is a function of collector capacitance rate, $\dot{m} C_{p} / A_{C} U_{L} F^{\prime}$, only. The fin efficiency factor, $F$, the most important parameter in the design of liquid type solar collector is written as $[6,7]$ :

$F=\tan h\left[\sqrt{\frac{U_{L}}{k \delta}}\left(\frac{s-d}{2}\right)\right] / \sqrt{\frac{U_{L}}{k \delta}}\left(\frac{s-d}{2}\right)$

\subsection{Solar collector performance prediction and tests}

The procedure for testing flat plate solar collectors has been described by a number of investigators. Although basically similar in approach, these methods differ in accounting for the variability of the collector loss coefficient $U_{L}$. Shewen et al [8] reported that, most of the authors are of the opinion that $U_{L}$ is a unique function of $\left(t_{f}-t_{a}\right) / I$, written under as:

$U_{L}=f_{n}\left[\left(\bar{t}_{f}-t_{a}\right) / I\right]$

and the thermal efficiency equation is written as:

$\eta_{t h}=F^{\prime}(\tau \alpha)-F^{\prime} U_{L}\left[\left(\bar{t}_{f}-t_{a}\right) / I\right]$

ASHARE [9] recommends the use of $F_{R}$ and therefore, $\Delta t=t_{i}-t_{a}$, whereas, NBS (National Bureau of Standards) recommends [10] the use of $F^{\prime}$ and $\Delta t=t_{m}-t_{a}$. Accordingly, the thermal efficiency equations are written as:

$\eta_{t h}=F_{R}\left[(\tau \alpha)-U_{L}\left(\Delta t_{m} / I\right)\right]$

and, $\eta_{t h}=F^{\prime}\left[(\tau \alpha)-U_{L}\left(\Delta t_{m} / I\right)\right]$

Authors [10] proposed the following set of equations to obtain the efficiency curves on the basis of NBS recommendations:

Case A : with air recycling, $\left(t_{i}>t_{a}\right)$

$$
\eta_{t h}=F^{\prime}\left[(\tau \alpha)-\frac{U_{L}\left\{\left(t_{o}-t_{a}\right)+\left(t_{i}-t_{a}\right)\right\}}{2 I}\right]
$$

and, $\eta_{t h}=2 G C_{p}\left[\left(t_{o}-t_{a}\right)-\left(t_{i}-t_{a}\right)\right] / 2 I$

Case B: Without air recycling, $\left(t_{i}-t_{a}\right)$

$$
\eta_{t h}=F^{\prime}\left[\tau \alpha-\frac{U_{L}\left(t_{o}-t_{a}\right)}{2 I}\right]
$$

and, $\mathrm{\eta}_{t h}=2 G C_{p}\left(t_{o}-t_{a}\right) / 2 I$

which, when written for $t_{i}=t_{a}$, yields respectively,

$$
\eta_{t h}=F^{\prime}\left[\tau \alpha-\frac{U_{L}\left(t_{o}-t_{i}\right)}{2 I}\right]
$$

and, $\eta_{t h}=2 G C_{p}\left(t_{o}-t_{i}\right) / 2 I$

Review [11] of the existing testing procedures reported that all the studies till then involved the outdoor testing of water heating collectors, using the instantaneous efficiency method given by: 
$\eta_{t h}=\left(Q_{u} / A_{C}\right) / I=\dot{m} C_{p}\left(t_{o}-t_{i}\right) / I$

One of the exception mentioned was that of the NASA Lewis Research Centre, which used indoor simulator. W.D.Lee used calorimetric approach for testing water heating collectors and gave the following equation for efficiency:

$$
\eta_{t h}=\left(Q_{u} / A_{C}\right) / I=\left(m^{\prime} C_{p}^{\prime} \frac{\overline{d t}}{d t^{\prime}}\right) / I
$$

Collector configuration for performance testing of the liquid and air heating collectors have been recommended and importance of accurate measurements of the incident solar energy, angular and transient response characteristic of the collector in such tests procedure has been discussed [11]. The set of equation used to represent the performance of collectors have been given [12] as:

$Q_{u} / A_{c}=F_{R}\left[I f_{1}-U_{L}\left(t_{i}-t_{a}\right)\right]$

$Q_{u} / A_{c}=F^{\prime}\left[I f_{1}-U_{L}\left(t_{a v}-t_{a}\right)\right] ; t_{a v}=\left(t_{o}+t_{i}\right) / 2$

$\eta_{t h}=Q_{u} / A_{c} I=G C_{p}\left(t_{o}-t_{i}\right) / I$

Equations for the collector efficiency factor and the loss coefficient for solar air heaters, commonly used: (a) flow over the absorber, (b) flow under the absorber and (c) flow on both sides of the absorber were developed [13]. It was claimed that these equations represented an improved version of the available relations for performance prediction since these include a number of influencing parameters usually neglected by previous investigators. A detailed study of testing procedures was carried out [14-16] including the study [15] of attainable accuracy of the operating parameters. Techniques used in the prediction of flat plate solar collector performance of non-metallic absorber plate analysis were developed [17]. Performance analysis of solar air heater is available [18].

\subsection{Solar air heater performance}

In the case of solar air heaters working on an open cycle, the inlet air temperature always coincides with the ambient temperature i.e., $t_{i}=t_{a}$. As such, the conventional Eq. (4) is not meaningful, Eq. (4) reduces to, $\eta_{t h}=F_{R}(\tau \alpha)$. Therefore, it is useful to utilize the following form of equation $[6,10,18]$. $\eta_{t h}=F_{o}\left[(\tau \alpha)-\frac{U_{L}\left(t_{o}-t_{a}\right)}{I}\right]$

where, $F_{o}$ is the factor of heat removal referred to the outlet temperature, expressed as [18]:

$F_{o}=G C_{p}\left[e^{\left(U_{L} F^{\prime} / G C_{p}\right)}-1\right] / U_{L}$

Further, performance can also be expressed as:

$\eta_{t h}=G C_{p}\left(t_{o}-t_{i}\right) / I$

For $t_{i}=t_{a}$, the variable reduced temperature of Eqs. (24) and (26) coincide. Therefore, Eqs. (24) and (26) could be represented on a single diagram having the same quantity in the abscissa $[10,18]$. This was considered the most suitable way to describe the characteristics of solar air collectors [10, 18]. An approximate analytical correction can be made to $F_{R}(\tau \alpha)$ and $F_{R} U_{L}$, when actual test results are not available [6]. It was proposed that the data be plotted $\eta_{t h}$ versus $\left(t_{a v}-t_{a}\right) / I$, instead of usual $\left(t_{i}-t_{a}\right) / I$, taking $t_{a v}=\left(t_{i}+t_{o}\right) / 2$. The performance equation then could be written as:

$\eta_{t h}=F_{a v}(\tau \alpha)-F_{a v} U_{L} \frac{t_{a v}-t_{a}}{I}$

where, $F_{a v}$, approximated to $F^{\prime}$ and correction for $F_{R}(\tau \alpha)$ and $F_{R} U_{L}$, could be obtained from the following equations [6]:

$F_{R}(\tau \alpha)=F_{a v}(\tau \alpha)\left[\frac{\dot{\mathrm{m}} C_{p} / A_{c}}{\dot{\mathrm{m}} C_{p} / A_{c}+F_{a v} U_{L} / 2}\right]$

$F_{R} U_{L}=F_{a v} U_{L}\left[\frac{\dot{\mathrm{m}} C_{p} / A_{c}}{\dot{\mathrm{m}} C_{p} / A_{c}+F_{a v} U_{L} / 2}\right]$

However, $\mathrm{\eta}_{t h}$, if plotted against $\left(t_{o}-t_{a}\right) / I$, often done for air heater test data $[10,18]$, the equation for $\eta_{t h}$ would be:

$\eta_{t h}=F_{o}(\tau \alpha)-F_{o} U_{L} \frac{\left(t_{o}-t_{a}\right)}{I}$

And, correction for $F_{R}(\tau \alpha)$ and $F_{R} U_{L}$, would then be:

$F_{R}(\tau \alpha)=F_{o}(\tau \alpha)\left[\left(\dot{\mathrm{m}} C_{p} / A_{c}\right) /\left(\dot{\mathrm{m}} C_{p} / A_{c}+F_{o} U_{L}\right)\right]$

$F_{R} U_{L}=F_{o} U_{L}\left[\left(\dot{\mathrm{m}} C_{p} / A_{c}\right) /\left(\dot{\mathrm{m}} C_{p} / A_{c}+F_{o} U_{L}\right)\right]$

Authors [19] averred that the thermal performance representation, testing procedure and mathematical models associated with the solar air collectors had not been developed to the same extent as for liquid collectors. The two fundamental differences between 
air and liquid solar collectors are (a) relatively poor thermal conductivity of the air resulting in lower absorber to the air heat transfer coefficient as compared to that for liquid collectors, which implies that the former have a strong dependence on flow rate, (b) most air collectors leak since it is not economical to build a perfectly sealed solar air collector. Experimental investigation of the effect of such variation of flow rate and inlet gage pressure on the thermal performance of an air collector was therefore, made [18]. The collector was tested at the flow rates $\left(0.01 \mathrm{~m}^{3} / \mathrm{s} . \mathrm{m}^{2}\right.$ and $\left.0.03 \mathrm{~m} \mathrm{~m}^{3} / \mathrm{s} . \mathrm{m}^{2}\right)$, recommends [19], when inlet gage pressure varied from $-150 \mathrm{~Pa}$ to $+150 \mathrm{~Pa}$.

\section{Results and Discussions.}

For solar air heaters, without recycling of carrier fluid (air), the conventional methods used for representing the thermal performance, i.e., plots of efficiency $\left(\mathrm{n}_{t h}\right)$ versus $\left(t_{i}-t_{a}\right) / I$, become ineffective because the abscissa value is always zero. Therefore, thermal performance of such solar air heaters has been represented on the basis of outlet air temperature, instead of inlet air temperature, [6, 10, 18, 19], and Eqs. (26) and (30) form the basis of representation of thermal efficiency in terms of various physical and meteorological parameters. For inlet fluid temperature, $\left(t_{i}\right)$, to be the same as ambient temperature, $\left(t_{a}\right)$, Eq. (30) takes the form:

$\eta_{t h}=F_{o}\left[(\tau \alpha)-\frac{U_{L}\left(t_{o}-t_{i}\right)}{I}\right]$

Performance of solar air heaters is a stronger function of mass flow rate as compared to that of liquid collectors because the changes in mass flow rate do not appreciably affect the performance in liquid collectors due to high values of absorber plate to fluid heat transfer coefficients. A single collector efficiency curve is therefore, reasonably sufficient to represent the behavior of liquid collector for any reasonable flow rate, whereas, in the case of solar air heaters, variation in air flow rate changes the thermal performance appreciably and large variations occur in collector efficiency. It has been recommended that in order to obtain reasonable reliable information with regard to the thermal performance of solar air heaters, these must be tested in a wide range of mass flow rates, each flow rate resulting in an efficiency curve [9]. It has been proposed [10] that for obtaining complete design information on such systems, one performance curve (efficiency versus $\left(t_{o}-t_{i}\right) / I$ ), superimposed with efficiency curves for different mass flow rates, are desirable for solar air heaters without recycling of air (i.e., $t_{i}$ being always equal to $t_{a}$ ). As such performance characteristics of solar air heater having wide range of mass flow rate have been represented typically [21] in Fig. 1, for artificially roughened solar heater, as also for smooth solar air heater. Artificial roughness provided on the absorber plate results in higher value of thermal performance [21].

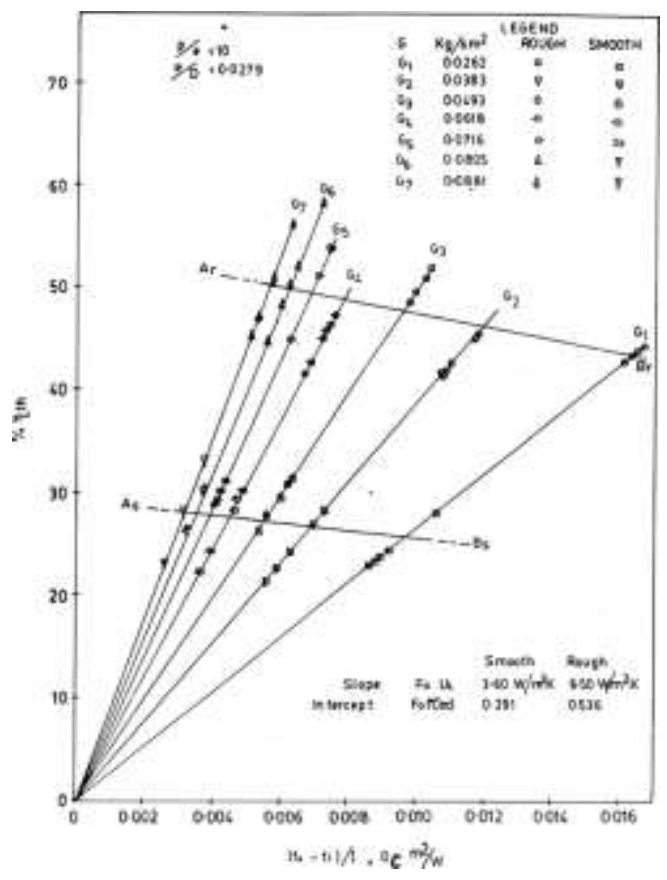

Fig. 1. Performance characteristics of solar air heaters.

Performance curves (straight lines) have been drawn by the least square fit method for both the roughened and smooth collector data on efficiency and temperature rise obtained by varying the mass flow rates, while each efficiency curve based on Eq. (26) has been drawn by joining the data points for a given flow rate and these when extrapolated are found to pass through the origin.

\subsection{Slope and Intercept of Performance Curves}

The conventional methods of representing the performance cannot be used for solar air heaters having inlet air always at ambient temperature, consequently, the slope and the intercept of the 
performance curves on efficiency axis cannot be interpreted in terms of heat removal factor, overall loss coefficient and overall transmittance-absorptance product of the system i.e., $F_{R} U_{L}$ and $F_{R}(\tau \alpha)$, respectively. However, for such systems, as proposed $[10,18]$ and expressed by Eq. (30), the slope and intercept are to be interpreted respectively as $F_{o} U_{L}$ and $F_{o}(\tau \alpha)$, when efficiency is plotted with air temperature rise to insolation ratio i.e., $\left(t_{o}-t_{i}\right) / I$ as the abscissa. These values have then been used to obtain the values of the performance parameters $F_{R}(\tau \alpha)$ and $F_{R} U_{L}$ using Eqs. (31) and (32) respectively. The values of the collector efficiency factor is determined using the following relationships $[6,8]$ respectively:

$F_{R} / F^{\prime}=\left(\dot{\mathrm{m}} C_{p} / A_{c} U_{L} F^{\prime}\right)\left[1-e^{-\left(A_{C} U_{L} F^{\prime} / \dot{\mathrm{m}} C_{p}\right)}\right]$

and $\quad F_{o}=G C_{p}\left[e^{\left(U_{L} F^{\prime} / G C_{p}\right)}-1\right] / U_{L}$

Eqs. (34) and (35) can be combined to yield a relationship for collector efficiency given as:

$F^{\prime}=\frac{\dot{\mathrm{m}} C_{p}}{A_{c}} \ln \left(\frac{F_{o} U_{L}}{F_{R} U_{L}}\right) / U_{L}$

The values of the slope and intercept, obtained, have been utilized to find out the values of $F_{R}$ and $F^{\prime}$, from Eqs. (28) and (29), and shown in Figs. 2 and 3 typically [21].

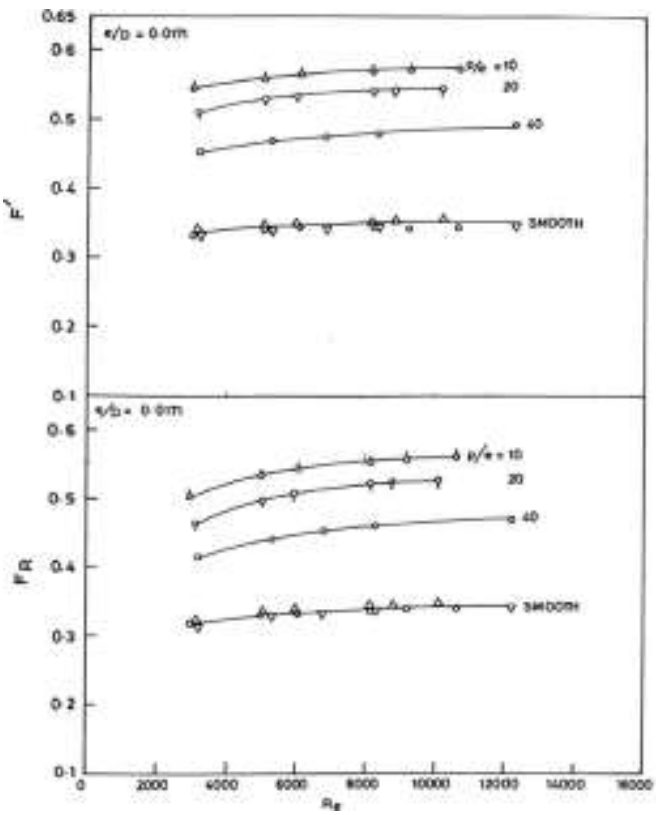

Fig. 2. Effect of p/e on collector heat removal factor and collector efficiency factor in solar air heater.

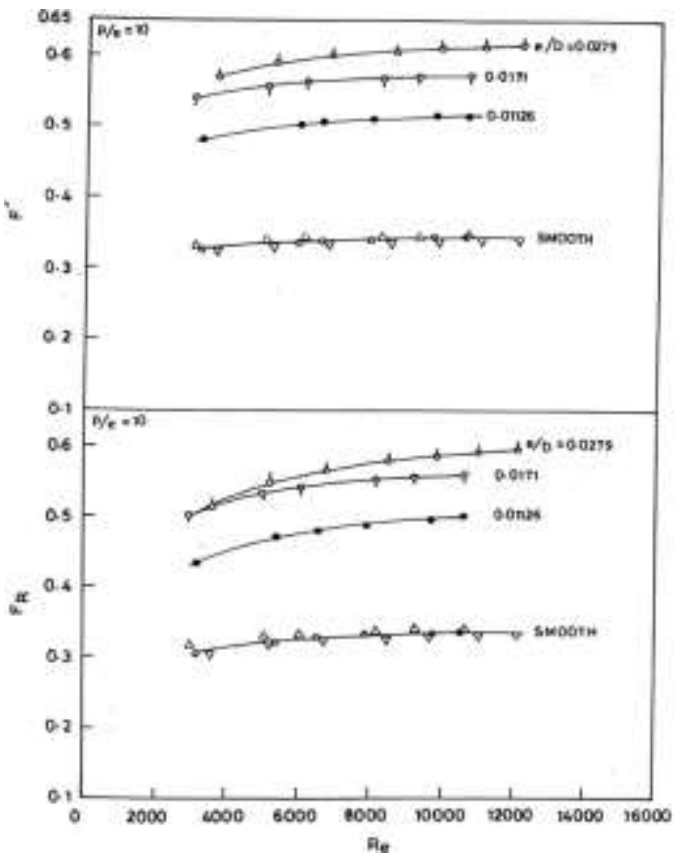

Fig. 3. Effect of e/D on collector heat removal factor and collector efficiency factor in solar air heater.

\section{Conclusions:-}

1. Solar air heaters usually operate without recycling of the carrier fluid (air) and their performance is very much mass flow rate dependent.

2. Conventional equations for representing performance of such solar air heater are not very realistic.

3. Performance characteristics of such solar air heater should be represented by modifying the conventional equations, on the basis of fluid inlet and outlet temperature.

4. The values of the slope $F_{o} U_{L}$ and intercept, $F_{o}(\tau \alpha)$, of the performance curve, could be utilized to predict the performance in term of the performance parameters, $F_{R} U_{L}$ and $F_{R}(\tau \alpha)$.

References:-

1. A.K. Patil, J. S Saini and K. Kumar, "A comprehensive review on roughness geometries and investigation techniques used in artificially roughened solar air heaters", Int. J. Renewable Energy Res. 2(1), (2012).

2. B. N. Prasad, Arun K. Behura, and L. Prasad, "Fluid flow and heat transfer analysis for heat transfer enhancement in three sided artificially roughened solar air heater", Sol. Energy, 105, 27-35 (2014).

3. B.N. Prasad, Ashwini Kumar, and K.D.P. Singh, "Optimization of thermo hydraulic performance in three 
sides artificially roughened solar air heaters", Sol. Energy, 111, 313-319 (2015).

4. H.C. Hottel, and A. Whillier, "Evaluation of flat plate collector performance", Trans. Conf. on the use of Solar Energy, 2(1), 74, University of Arizona Press (1958).

5. R.W. Bliss, "The derivation of several plate efficiency factors useful in the design of flat plate solar heat collectors", Solar Energy, 3, 55-64 (1959).

6. J.A. Duffie, and W.A. Beckman, "Solar Energy Thermal Process", Wiley Interscience, New York (1980).

7. Ted, J. Jansen, "Solar Engineering Technology", Prentice Hall, New Jersy (1985).

8. E.C. Shewen, and K.G.T. Holland, "Equations for representing the $U_{L}$-dependance in collector test procedure", Proc. ISES, Silver Jubilee Congress, Atlanta, Georgia, 1, 360-364, May (1979).

9. ASHARE Standard, 93-77, Methods of testing to determine the thermal performance of solar collectos (1977).

10. T.A. Reddy, and C.L. Gupta, "Generating application design data for solar air heating systems", Solar Energy, 25, 527-530 (980).

11. E. James, Hill, and R. Elmer, "Streed, A method of testing for rating solar collector based on thermal performance", Solar Energy, 18, 421-428 (1976).

12. C.L. Gupta, and H.P. Garg, "Performance studies on solar air heaters", Solar Energy,11(1), 25-31(1967).
13. Blaine, F. Parker, "Derivation of efficiency and loss factor for solar air heaters", Solar Energy, 26, 27-32 (1981).

14. D. Proctor, "A generalized method for testing all classes of solar collector-I, attainable accuracy", Solar Energy, 32 (3), 377-386 (1984).

15. D. Proctor, "A generalized method for testing all classes of solar collector-II, Evaluation of collector thermal constant", Solar Energy, 32 (3), 387-394 (1984).

16. D. Proctor, "A generalized method for testing all classes of solar collector-III, Linearized efficiency equation", Solar Energy, 32 (3), 395-399 (1984).

17. C. Frank, O'. Brien-Bernini and Jon G. McGowan, "Performance modeling of non-metallic flat plate solar collector", Solar Energy, 33 (3/4), 305-319 (1984).

18. P. Biondi, L. Cicala, and G. Farina, "Performance analysis of solar air heaters of conventional design", Solar Energy, 41 (1), 101-107 (1988).

19. M.A. Bernier, and E.G. Plett, "Thermal performance representation and testing of air solar collectors", Trans. ASME, 110, 74-81 (1988).

20. ASHARE standard 93-86, Method of testing to determine the thermal performance of solar collectors (1986).

21. Prasad, B.N., Thermel performance of artificial roughened solar air heaters, Elsevier, Solar Energy, 91, 59-67 (2013). 